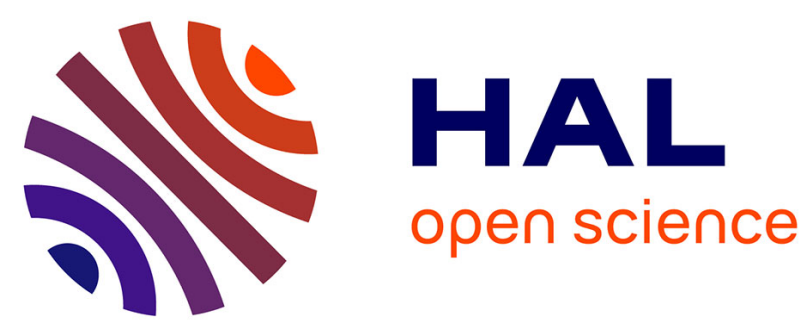

\title{
Multicomponent reactions in ionic liquids: convenient and ecocompatible access to the 2,6-DABCO core
} Zhor El Asri, Yves Génisson, F. Guillen, Olivier Baslé, Nicolas Isambert, Maria del Mar Sanchez Duque, Sonia Ladeira, Jean Rodriguez, Thierry Constantieux, Jean-Christophe Plaquevent

\section{To cite this version:}

Zhor El Asri, Yves Génisson, F. Guillen, Olivier Baslé, Nicolas Isambert, et al.. Multicomponent reactions in ionic liquids: convenient and ecocompatible access to the 2,6-DABCO core. Green Chemistry, 2011, 13, pp.2549-2552. 10.1039/c1gc15635g . hal-00681302

\section{HAL Id: hal-00681302 https://hal.science/hal-00681302}

Submitted on 21 Sep 2012

HAL is a multi-disciplinary open access archive for the deposit and dissemination of scientific research documents, whether they are published or not. The documents may come from teaching and research institutions in France or abroad, or from public or private research centers.
L'archive ouverte pluridisciplinaire $\mathbf{H A L}$, est destinée au dépôt et à la diffusion de documents scientifiques de niveau recherche, publiés ou non, émanant des établissements d'enseignement et de recherche français ou étrangers, des laboratoires publics ou privés. 


\title{
Multicomponent reactions in ionic liquids: convenient and ecocompatible access to the 2,6-DABCO core $\uparrow$
}

\author{
Zhor El Asri, ${ }^{a}$ Yves Génisson, ${ }^{a}$ Frédéric Guillen, ${ }^{a}$ Olivier Baslé, ${ }^{b}$ Nicolas Isambert, ${ }^{b}$ \\ Maria del Mar Sanchez Duque, ${ }^{b}$ Sonia Ladeira, ${ }^{c}$ Jean Rodriguez, ${ }^{b}$ Thierry Constantieux ${ }^{* b}$ and \\ Jean-Christophe Plaquevent $* a$
}

Herein we describe the use of ionic liquids as complementary new media for multicomponent reactions leading to the 2,6-diazabicyclo[2.2.2]octane core. The reaction took place efficiently in ionic liquid solvents instead of toluene, giving overall better results (faster rate, higher concentration) and allowing generalization to hitherto unreactive substituted Michael acceptors. In these cases, the use of molecular sieves, acting as a heterogeneous catalyst in the preliminary study in molecular solvents, could be totally excluded thanks to the promoting properties of the ionic liquid solvent, which could be recycled and reused up to five times. Complete diastereoselectivity was observed at one of the bridge positions, as assigned by $\mathrm{X}$-ray analysis.

\section{Introduction}

In the context of sustainable chemistry, ${ }^{1}$ the implementation of methodologies giving selective access to elaborate scaffolds, while combining molecular diversity ${ }^{2}$ with eco-compatibility, ${ }^{3}$ is a great challenge for organic chemists. Thanks to their ability to generate only one adduct from three or more reactants in a single operation with high atom economy ${ }^{4}$ and bond forming efficiency, ${ }^{5}$ multicomponent reactions (MCRs) ${ }^{6}$ now constitute an established approach to reach this ideal goal. ${ }^{7}$ Due to environmental concerns, the investigation of greener alternatives to conventional organic solvents has resulted in considerable interest in the use of reusable room temperature ionic liquids (RTILs). ${ }^{8}$ Furthermore, the user friendly and adjustable properties of these salts have prompted numerous applications, not only as environmentally benign reaction media, but also as catalysts, ${ }^{9}$ task-specific reagents, ${ }^{10 a}$ and chirality transfer media ${ }^{10 b}$ From this perspective, combining the synthetic potential of MCRs with the dual properties of RTILs as

${ }^{a}$ Laboratoire de Synthèse et Physicochimie de Molécules d'Intérêt Biologique UMR-CNRS 5068, Université Paul Sabatier, 118 route de Narbonne, 31062, Toulouse, France.

E-mail: plaquevent@chimie.ups-tlse.fr; Fax: +33(0)561556011, Tel: +33 (0)561556299

${ }^{b}$ Université Aix-Marseille UMR-CNRS 6263 iSm2, Campus Saint Jérome - Case 531, 13397, Marseille Cedex 20, France.

E-mail: thierry.constantieux@univ-cezanne.fr; Fax: +33 (0)491289187; Tel: $+33(0) 491282874$

'SFTCM, FR 2599, Université Paul Sabatier, 118 route de Narbonne, 31062, Toulouse, France

$\uparrow$ CCDC reference number 800251 . For crystallographic data in CIF or other electronic format see DOI: $10.1039 / \mathrm{clgc} 15635 \mathrm{~g}$ solvents and promoters has resulted in the development of new and promising eco-compatible organic transformations. ${ }^{11}$ The aim of this paper is to illustrate this approach through the three-component synthesis of new heterocycles having a 2,6-diazabicyclo[2.2.2]octane (2,6-DABCO) core, involving the promoting ability of simple RTILs.

A few years ago, some of us reported a new molecular sieve (MS)-promoted multicomponent domino reaction affording access to polyfunctionalized 2,6-DABCO cores from $\beta$ ketoamides (Scheme 1). ${ }^{12}$ This stereoselective sequence generates original molecules with a high level of complexity from simple achiral substrates while respecting environmental criteria such as step- and atom-economy, the limitation of waste products ${ }^{13}$ and the use of a recoverable heterogeneous catalyst. ${ }^{14}$ However, this transformation cannot be definitively considered as a green procedure because it is hampered by drawbacks (see later discussion). Moreover, although various ketoamides and nucleophiles were tolerated, the molecular diversity was limited by the nature of the Michael acceptor, good results being only obtained with acrolein.<smiles>C=CC=Cc1ccccc1NC(=O)CC(=O)c1ccccc1</smiles>
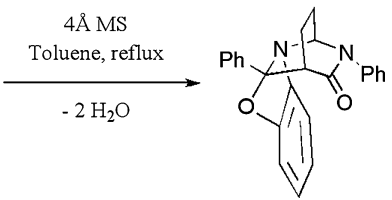

Scheme 1

Herein, we wish to disclose our preliminary results on the benefits of RTILs in this chemistry. Their use as reaction media 
instead of molecular solvents allows increased reactivity, generalizing the process to hitherto unreactive substituted Michael acceptors and reducing or even sometimes avoiding the use of MSs.

\section{Results and discussion}

Since the reactions studied so far involved acrolein as the Michael acceptor, we first embarked on the evaluation of RTILs as solvents in the model reaction depicted in Scheme 1.

We first reproduced the reported standard conditions using freshly distilled toluene as the solvent, and acrolein, orthoaminophenol and 2-benzoylacetanilide as reagents.

Typical yields for this experiment were around $60 \%$ of analytically pure compound after chromatography. Although efficient, the reaction suffers from several drawbacks with respect to green chemistry concepts, i.e. the long reaction time $(24 \mathrm{~h})$, high temperature in a toxic molecular solvent (refluxing toluene) and the overall large excess of MS ( $c a .6 \mathrm{~g}$ for $200 \mathrm{mg}$ reagent, i.e. $c a .3000 \mathrm{wt}^{\%} \%$ ).

When transposing this multicomponent synthesis to various ILs (Scheme 2), unexpected observations were made. We initially believed that the use of hydrophilic ILs, potentially able to capture the produced water molecules, would be useful in order to avoid the large excess of MS. In Table 1 are depicted the most significant observations of this first set of experiments.<smiles>C=CC=[NH+]c1ccccc1NC(=O)CC(=O)c1ccccc1</smiles>

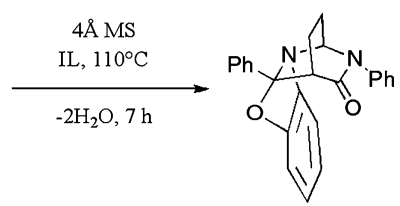

\section{Scheme 2}

We first examined the potential role of the anion (Table 1, entries 1 to 7) for bmim ILs. Most reactions gave very low yields and complex mixtures of products, except when using $[\mathrm{bmim}]\left[\mathrm{BF}_{4}\right]$ and $[\mathrm{bmim}]\left[\mathrm{NTf}_{2}\right]$. In these two solvents, yields were even higher than in toluene, respectively, 65 and $75 \%$

Table 1 Screening of RTILs ${ }^{a}$

\begin{tabular}{llll}
\hline Entry & IL cation & IL anion & Yield (\%) \\
\hline 1 & bmim & $\mathrm{Cl}$ & - \\
2 & bmim & $\mathrm{BF}_{4}$ & 65 \\
3 & bmim & $\mathrm{PF}_{6}$ & - \\
4 & bmim & $\mathrm{NTf}_{2}$ & 75 \\
5 & bmim & Tartrate & - \\
6 & bmim & H-Tartrate & - \\
7 & bmim & $\mathrm{N}(\mathrm{CN})_{2}$ & - \\
8 & bmmim & $\mathrm{NTf}_{2}$ & - \\
9 & $1,3-$-Bisphenylmethyl imidazolium & $\mathrm{BF}_{4}$ & - \\
10 & $1,3-$ Bisphenylmethyl imidazolium & $\mathrm{NTf}_{2}$ & - \\
11 & Butylmethyl pyrrolidinium & $\mathrm{NTf}_{2}$ & - \\
12 & $(\text { dihex })_{2}$ dmg & $\mathrm{NTf}_{2}$ & - \\
13 & bmim & $\mathrm{NTf}_{2}+\mathrm{Cl}$ & - \\
14 & bmim + bmmim & $\mathrm{NTf}_{2}$ & -
\end{tabular}

${ }^{a}$ Reaction conditions: A solution of $80 \mathrm{mg}$ of $\beta$-ketoamide ( 1 equiv.), $92 \mathrm{mg}$ of acrolein (5 equiv.), $36 \mathrm{mg}$ of 2 -aminophenol (1 equiv.) and $600 \mathrm{mg}$ of $4 \AA \mathrm{MS}(750 \mathrm{w} \%)$ in $1 \mathrm{~mL}$ of IL was stirred at $110^{\circ} \mathrm{C}$ for $7 \mathrm{~h}$. Yields are given for analytically pure chromatographed material. Each reaction was at least duplicated. after chromatography (Table 1, entries 2 and 4, and Scheme 2). We were surprised to observe that both hydrophilic $\left[\mathrm{BF}_{4}\right]$ and hydrophobic $\left[\mathrm{NTf}_{2}\right]$ anions were suitable for this test reaction. Regarding the role of the cation (Table 1, entries 2, 4 and 8 to 12), we observed that either the absence of acidic protons in the cation or steric hindrance led to a complete loss of reactivity. Finally, mixing efficient and ineffective ILs (Table 1, entries 13 and 14) totally inhibited the reaction. We assume that very fine tuning of the IL is required for acrolein stability and reactivity in an IL medium. Indeed, our further studies will focus on the potential role of the acidity of ILs in promoting the reaction. A recent report by Cui et al. has shown the great influence of this parameter on catalysis, ${ }^{15}$ which could strongly modify acrolein stability towards polymerization, as well as the rate of enolization, Michael addition and dehydration in the model reaction.

We thus succeeded in replacing the molecular solvent, obtaining quantitative conversion and a high yield after purification. More importantly were the high reaction rate increase (7 vs. $24 \mathrm{~h}$ ) and the significant decrease in the amount of MS (by ca. 4 times), although it was not possible to completely avoid their use in the reaction involving acrolein. Having in hand this rather robust multicomponent reaction in ILs, we then embarked on a more systematic study of Michael acceptors, which represented a major limitation in molecular solvents.

The main results of this study are reported below (Scheme 3 and Table 2) using cinnamaldehyde $\left(R^{1}=P h, R^{2}=H\right)$, crotonaldehyde $\left(\mathrm{R}^{1}=\mathrm{Me}, \mathrm{R}^{2}=\mathrm{H}\right)$, tiglic aldehyde $\left(\mathrm{R}^{1}=\mathrm{R}^{2}=\mathrm{Me}\right)$ and methacrolein $\left(\mathrm{R}^{1}=\mathrm{H}, \mathrm{R}^{2}=\mathrm{Me}\right)$ as Michael acceptors. We systematically compared the results in toluene with the two ionic media selected from the previous set of experiments, either in the presence $(+)$ or in the absence (-) of MS. Indeed, this additive was suspected to contribute to the stabilization of acrolein towards polymerization, and the new acceptors were believed to be more stable than the latter under the reaction conditions.

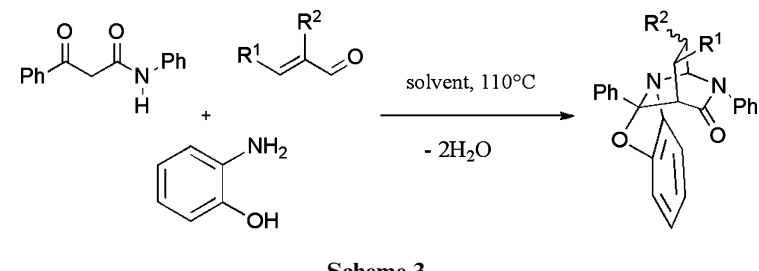

Scheme 3

In most cases, we were pleased to observe even more robust and reliable transformations with good conversions, affording synthetically useful isolated yields (45 to $70 \%$ ) of the expected substituted heterocycles with generally better results in $[$ bmim $]\left[\mathrm{NTf}_{2}\right]$. New trends can be drawn from this set of experiments. First, the results observed in IL solvents compare favourably with the typical conditions in toluene (Table 2, entries 1, 6, 11 and 16), with improved yields in many cases. Finally and maybe most importantly, it was possible to obtain similar and sometimes even better results in the complete absence of molecular sieves, in sharp contrast with the reactions using acrolein (Table 2, entries 4 and 5, 9 and 10, 14 and 15, and 19). To the best of our knowledge, this finding is unprecedented and clearly points out the promoting ability of ILs. 
Table 2 Scope of the reaction ${ }^{a}$

\begin{tabular}{|c|c|c|c|c|c|}
\hline Entry & $\mathrm{R}^{1}$ & $\mathrm{R}^{2}$ & Solvent & MS & Yield $(\%)$ \\
\hline 1 & $\mathrm{Ph}$ & $\mathrm{H}$ & Toluene & + & 45 \\
\hline 2 & $\mathrm{Ph}$ & $\mathrm{H}$ & {$[\mathrm{bmim}]\left[\mathrm{NTf}_{2}\right]$} & + & 55 \\
\hline 3 & $\mathrm{Ph}$ & $\mathrm{H}$ & {$[\mathrm{bmim}]\left[\mathrm{BF}_{4}\right]$} & + & 50 \\
\hline 4 & $\mathrm{Ph}$ & $\mathrm{H}$ & {$[\mathrm{bmim}]\left[\mathrm{NTf}_{2}\right]$} & - & 57 \\
\hline 5 & $\mathrm{Ph}$ & $\mathrm{H}$ & {$[\mathrm{bmim}]\left[\mathrm{BF}_{4}\right]$} & - & 50 \\
\hline 6 & $\mathrm{Me}$ & $\mathrm{H}$ & Toluene & + & 70 \\
\hline 7 & $\mathrm{Me}$ & $\mathrm{H}$ & {$[\mathrm{bmim}]\left[\mathrm{NTf}_{2}\right]$} & + & 65 \\
\hline 8 & $\mathrm{Me}$ & $\mathrm{H}$ & {$[\mathrm{bmim}]\left[\mathrm{BF}_{4}\right]$} & + & 55 \\
\hline 9 & $\mathrm{Me}$ & $\mathrm{H}$ & {$[\mathrm{bmim}]\left[\mathrm{NTf}_{2}\right]$} & - & 65 \\
\hline 10 & $\mathrm{Me}$ & $\mathrm{H}$ & {$[\mathrm{bmim}]\left[\mathrm{BF}_{4}\right]$} & - & 60 \\
\hline 11 & $\mathrm{Me}$ & $\mathrm{Me}$ & Toluene & + & 46 \\
\hline 12 & $\mathrm{Me}$ & $\mathrm{Me}$ & {$[\mathrm{bmim}]\left[\mathrm{NTf}_{2}\right]$} & + & 60 \\
\hline 13 & $\mathrm{Me}$ & $\mathrm{Me}$ & {$[\mathrm{bmim}]\left[\mathrm{BF}_{4}\right]$} & + & 50 \\
\hline 14 & $\mathrm{Me}$ & $\mathrm{Me}$ & {$[\mathrm{bmim}]\left[\mathrm{NTf}_{2}\right]$} & - & 65 \\
\hline 15 & $\mathrm{Me}$ & $\mathrm{Me}$ & {$[\mathrm{bmim}]\left[\mathrm{BF}_{4}\right]$} & - & 52 \\
\hline 16 & $\mathrm{H}$ & $\mathrm{Me}$ & Toluene & + & 40 \\
\hline 17 & $\mathrm{H}$ & $\mathrm{Me}$ & {$[\mathrm{bmim}]\left[\mathrm{NTf}_{2}\right]$} & + & 47 \\
\hline 18 & $\mathrm{H}$ & $\mathrm{Me}$ & {$[\mathrm{bmim}]\left[\mathrm{BF}_{4}\right]$} & + & 36 \\
\hline 19 & $\mathrm{H}$ & $\mathrm{Me}$ & {$[\mathrm{bmim}]\left[\mathrm{NTf}_{2}\right]$} & - & 44 \\
\hline 20 & $\mathrm{H}$ & $\mathrm{Me}$ & {$[\mathrm{bmim}]\left[\mathrm{BF}_{4}\right]$} & - & 38 \\
\hline
\end{tabular}

a Notes: Similar results were obtained when using either 5 or 1.2 equiv. of the Michael acceptor. Yields are given for analytically pure chromatographed material. Each reaction was at least duplicated. Reactions in toluene were carried out for $24 \mathrm{~h}$ and needed $3000 \mathrm{wt} \%$ of $4 \AA \mathrm{MS}$

We selected the reaction depicted in Table 2, entry 9 for solvent-recycling studies, a very promising aspect of ILs in the context of sustainable chemistry. First, we adopted an optimized procedure by thoroughly drying and de-gassing $[\mathrm{bmim}]\left[\mathrm{NTf}_{2}\right]$, using freshly distilled crotonaldehyde and reducing the reaction time to $5 \mathrm{~h}$. To our delight, the yield was significantly improved up to $86 \%$. When using this procedure at a 5 -times larger scale, recycling of the IL proved to be fully practical for up to 5 runs without any significant alteration in yield (Fig. 1).

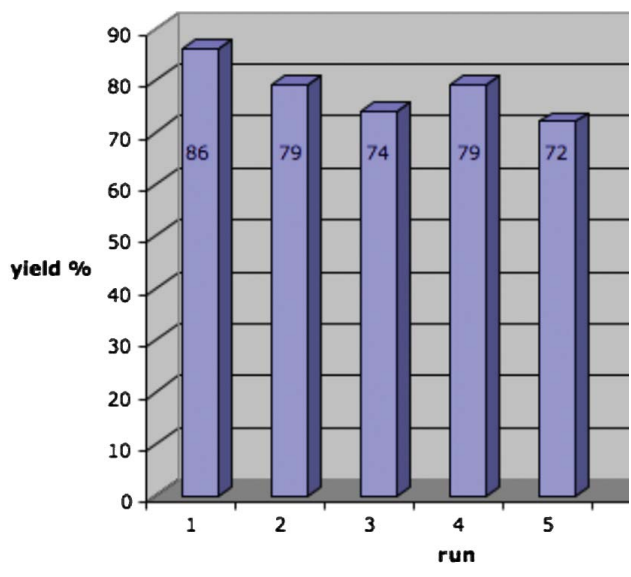

Fig. 1 Study of the recyclability of the reaction medium.

In addition to these findings, we wish to stress that this new series of compounds bears one or two additional stereogenic centres compared to the previous one. It was thus of important interest to assess the diastereoselectivity of the reaction. A single pure diastereomer was obtained with 3-substituted aldehydes (Table 2, entries 1-10), while 2,3-disubstituted aldehydes
(Table 2, entries 11-15) provided a mixture of only two diastereomers in a $54: 46$ ratio (as determined by ${ }^{1} \mathrm{H}$ NMR analysis). Similarly, 2-substituted aldehydes (Table 2, entries 1620) gave a mixture of two diastereomers in a $3: 1$ ratio. In the first case, the relative configuration of the newly created stereogenic centre was unambiguously established by the $\mathrm{X}$-ray diffraction analysis of a single crystal of the crotonaldehyde adduct $\left(\mathrm{R}^{1}=\right.$ $\left.\mathrm{Me}, \mathrm{R}^{2}=\mathrm{H}\right)($ Fig. 2$) . \dagger$ In particular, the methyl substituent was found to be oriented away from the sterically-demanding phenyl ring of the aminal quaternary carbon atom. Despite the total diastereoselectivity obtained for the new chiral centre coming from the $\gamma$-position of the acceptor $\left(\mathrm{R}^{1}=\mathrm{Me}, \mathrm{Ph}\right)$, no stereocontrol was recorded for the chiral centre coming from the $\alpha$-position $\left(\mathrm{R}^{2}=\mathrm{Me}\right)$. These stereochemical observations represent a precious clue for mechanistic insights.

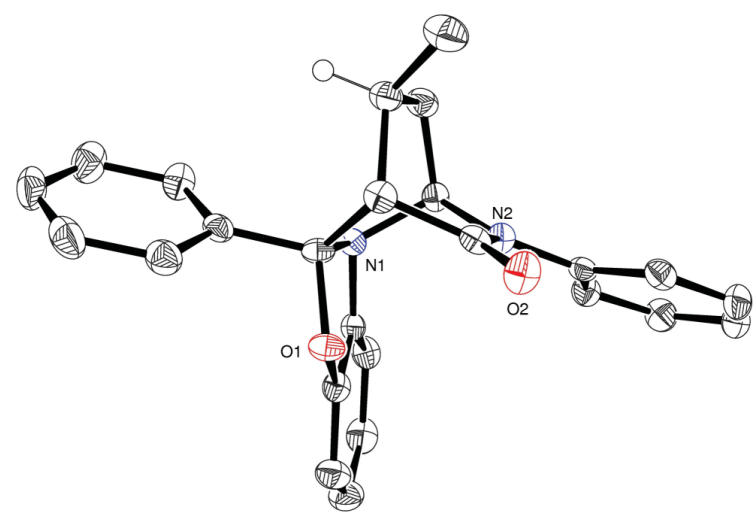

Fig. 2 Molecular view of the crotonaldehyde adduct in the solid state (thermal ellipsoids at $50 \%$ probability); hydrogens are omitted for clarity, except on the asymmetric carbon.

\section{Conclusions}

In this study we describe the use of ILs for multicomponent reactions leading to 2,6-diazabicyclo[2.2.2]octane cores. We demonstrate that the reaction not only occurred in IL solvents in place of toluene but that even better results were obtained. Significantly shorter reaction times at higher concentration were systematically observed, even with hitherto unreactive Michael acceptors. Except when reacting acrolein, the use of molecular sieves could be totally avoided thanks to the promoting properties of the chosen RTILs; with 3-substituted aldehydes, perfect diastereoselectivity was observed. The IL could be recycled and reused up to 5 times. This series of new findings constitutes a step forward for the development of multicomponent syntheses under green conditions. ${ }^{11}$ We are currently investigating the reaction of new $\beta$-dicarbonyl compounds, as well as considering mechanistic issues and chirality transfer by means of chiral ionic media. ${ }^{10}$

\section{Experimental}

Multicomponent reaction using crotonaldehyde as a Michael acceptor $\left(R^{1}=M e, R^{2}=H\right)$

In a $10 \mathrm{~mL}$ flask under argon were introduced the $\beta$-ketoamide (80 mg, $0.33 \mathrm{mmol}, 1$ equiv.), crotonaldehyde (either 5 or 
1.2 equiv.) and ortho-aminophenol ( $36 \mathrm{mg}, 0.33 \mathrm{mmol}, 1$ equiv.) in $1 \mathrm{~mL}$ of the chosen IL. After stirring for $7 \mathrm{~h}$ at $110^{\circ} \mathrm{C}$, the reaction mixture was extracted with 1,1,1-trichloroethane. The organic layer was evaporated and the resulting material purified by column chromatography (petroleum ether: ethyl acetate: $70: 30)$ to give the expected adduct $(65 \%)$ as a white solid (mp 251-252 ${ }^{\circ} \mathrm{C}$ ).

Recycling experiments were conducted on a $1.65 \mathrm{mmol}$ scale using 1.2 equiv. of freshly distilled crotonaldehyde in $5 \mathrm{~mL}$ of carefully dried $\left(40{ }^{\circ} \mathrm{C} / 10^{-3} \mathrm{mbar}\right.$, overnight) [bmim] $\mathrm{NTf}_{2}$ for $5 \mathrm{~h}$ at $110^{\circ} \mathrm{C}$ under nitrogen. After product extraction, the IL was washed with water and dried again under the same conditions before being used for the next run. The crude material was purified by column chromatography (petroleum ether: $\mathrm{CH}_{2} \mathrm{Cl}_{2}$ : ethyl acetate: $\left.50: 25: 25\right)$ to give the expected adduct as an of-white solid (see Fig. 1 for yields).

Recrystallization from a dichloromethane : heptane solution, $5 \mathrm{~d}$, rt. TLC (petroleum ether: AcOEt: $70: 30$ ): $R_{\mathrm{f}} 0.25$. IR $\left(\mathrm{KBr}, \mathrm{cm}^{-1}\right): 3428,1678,1635,1481,1410,1265,1244 .{ }^{1} \mathbf{H}$ NMR $\left(\mathrm{CDCl}_{3}, 300 \mathrm{MHz}\right): 1.17(3 \mathrm{H}, \mathrm{d}, J=7.1 \mathrm{~Hz}), 1.67(1 \mathrm{H}, \mathrm{ddd}, J=$ $3.3 \mathrm{~Hz}, J=4.2 \mathrm{~Hz}, J=12.9 \mathrm{~Hz}), 1.96-2.09(1 \mathrm{H}, \mathrm{m}), 2.6(1 \mathrm{H}, \mathrm{ddd}$, $J=2.3 \mathrm{~Hz}, J=9.8 \mathrm{~Hz}, J=12.9 \mathrm{~Hz}), 3.39(1 \mathrm{H}, \mathrm{d}, J=2.4 \mathrm{~Hz})$, $5.15(1 \mathrm{H}, \mathrm{dd}, J=2.3 \mathrm{~Hz}, J=3.3 \mathrm{~Hz}), 6.7-7.7\left(14 \mathrm{H}_{\text {arom }}, \mathrm{m}\right) .{ }^{13} \mathbf{C}$ NMR $\left(\mathrm{CDCl}_{3}\right): 167.7,151.9,139.5,139.15,137.1,129.2(2 \mathrm{C})$, 128.9, 128.4 (2C), 126.7, 126.5 (2C), 125.5, 125.2 (2C), 121.1, $116.3,109.7,104.4,78.3,55.9,36.2,23.9,21.7$. MS (CI) $m / z$ : $383[\mathrm{M}+\mathrm{H}]\left(100 \%\right.$, exact mass 382.17 for $\left.\mathrm{C}_{25} \mathrm{H}_{22} \mathrm{~N}_{2} \mathrm{O}_{2}\right)$. Anal. calc. C: 78.51; H: 5.80; N: 7.32; found: C: 78.65; H: 5.94; N: $7.17 \%$

\section{Crystal structure determination}

Data were collected at low temperature $(180 \mathrm{~K})$ on a Bruker Kappa Apex II diffractometer using graphite-monochromated Mo-K $\alpha$ radiation $(\lambda=0.71073 \AA)$ and equipped with an Oxford Cryosystems Cryostream cooler device. The structure was solved by direct methods (SIR92) ${ }^{16}$ and all non-hydrogen atoms were refined anisotropically using the least-squares method on $F^{2} \cdot{ }^{17} \dagger$

\section{Acknowledgements}

The French National Research Agency (ANR) is gratefully acknowledged for financial support (ANR-07-CP2D-06). The authors also acknowledge financial and technical support from
Aix-Marseille Université, Université Paul Sabatier, the CNRS and the French Research Ministry.

\section{Notes and references}

1 Special issue on Green Chemistry, see: (a) Chem. Rev, 2007, 107, 2167-2820; (b) P. Anastas and N. Eghbali, Chem. Soc. Rev., 2010, 39, $301-312$.

2 T. E. Nielsen and S. L. Schreiber, Angew. Chem., Int. Ed., 2008, 47, $48-56$.

3 We define eco-compatible as meaning both economically and ecologically compatible: Y. Coquerel, T. Boddaert, M. Presset, D. Mailhol and J. Rodriguez, in Ideas in Chemistry and Molecular Sciences: Advances in Synthetic Chemistry, ed. B. Pignataro, Wiley-VCH, Weinheim, Germany, 2010, ch. 9, pp. 187-202.

4 B. M. Trost, Acc. Chem. Res., 2002, 35, 695-705.

5 P. A. Wender, V. A. Verma, T. J. Paxton and T. H. Pillow, Acc. Chem. Res., 2008, 41, 40-49.

6 (a) Multicomponent Reactions, ed. J. Zhu and H. Bienaymé, WileyVCH, Weinheim, 2005; (b) F. Liéby-Muller, C. Simon, T. Constantieux and J. Rodriguez, QSAR Comb. Sci., 2006, 25, 432-438; (c) D. Bonne, Y. Coquerel, T. Constantieux and J. Rodriguez, Tetrahedron: Asymmetry, 2010, 21, 1085-1109; (d) M. del Mar Sanchez Duque, C. Allais, N. Isambert, T. Constantieux, J. Rodriguez, in Topics in Heterocyclic Chemistry, vol. 23, ed. R. Orru, 2010, pp. 227 277.

7 The concept of "ideal synthesis" was first introduced in 1997: P. A. Wender, S. T. Handy and D. L. Wright, Chem. Ind., 1997, 765-768.

8 (a) Ionic Liquids in Synthesis, ed. P. Wasserscheid and T. Welton, Wiley-VCH, Weinheim, 2nd edn, 2008; (b) J. P. Hallet and T. Welton, Chem. Rev., 2011, 111, 3508-3576.

9 J. Durand, E. Teuma and M. Gomez, C. R. Chim., 2007, 10, 152-177.

10 (a) B. Ni and A. D. Headley, Chem.-Eur. J., 2010, 16, 44264436; (b) C. Baudequin, D. Brégeon, J. Levillain, F. Guillen, J.-C. Plaquevent and A.-C. Gaumont, Tetrahedron: Asymmetry, 2005, 16, 3921-3945.

11 For a recent review, see: N. Isambert, M. del Mar Sanchez Duque, J.-C. Plaquevent, Y. Génisson, J. Rodriguez and T. Constantieux, Chem. Soc. Rev., 2011, 40, 1347-1357.

12 F. Liéby-Muller, T. Constantieux and J. Rodriguez, J. Am. Chem. Soc., 2005, 127, 17176-17177.

13 In this sequence, water is the only by-product.

$144 \AA$ molecular sieves act both as a dehydrating agent and as a heterogeneous catalyst of the Michael addition, the first step of the domino sequence. For more details, see: $(a)$ C. Simon, J.-F. Peyronel and J. Rodriguez, Org. Lett., 2001, 3, 2145-2148; (b) F. Liéby-Muller, C. Allais, T. Constantieux and J. Rodriguez, Chem. Commun., 2008, 4207-4209.

15 X. Cui, S. Zhang, F. Shi, Q. Zhang, X. Ma, L. Lu and Y. Deng, ChemSus Chem, 2010, 3, 1043-1047.

16 A. Altomare, G. Cascarano, C. Giacovazzo and A. Guagliardi, J. Appl. Crystallogr., 1993, 26, 343-350.

17 G. M. Sheldrick, SHELXL-97, Program for Crystal Structure Refinement, University of Göttingen, 1997. 